\title{
MALLART, Fábio. 2014. Cadeias dominadas: a Fundação Casa, suas dinâmicas e as trajetórias de jovens internos. São Paulo: Terceiro Nome. 264p.
}

\section{Vinícius Prado Januzzi} $(\mathrm{UnB})$
Escrito por Fábio Mallart, Cadeias Dominadas: a Fundação Casa, suas dinâmicas e as trajetórias de jovens internos é o fruto mais consolidado de sua dissertação de mestrado defendida junto ao Programa de Pós-Graduação em Antropologia Social da Universidade de São Paulo (PPGAS/USP). Trata-se de obra singular, pela narrativa apresentada, pela perspicácia antropológica desenvolvida pelo autor e, não por menos, pela relevância acadêmica e política do material com o qual trabalha.

Em tempos de debates dos mais diversos níveis sobre a maioridade penal no Brasil, pode-se dizer que a obra se apresenta a nós, leitoras e leitores, no lugar e na hora certos. Explico: ao longo de seis anos, entre 2004 e 2009, o pesquisador viveu os mundos possíveis da Fundação CASA (Centro de Atendimento Socioeducativo ao Adolescente), aprofundando-se no universo daqueles agentes que ali se movem e experienciam o cotidiano do nosso sistema de encarceramento. Reside aí uma das primeiras contribuições do autor: narrar etnograficamente, nos modos como viveu e a partir das relações nas quais se envolveu, realidades muitas vezes desconhecidas e ignoradas por parte de quaisquer que sejam as propostas de reformulações normativas de nossa lógica carcerária.

Dado esse contexto, Cadeias Dominadas tem um objetivo claro, imbuído de dois pressupostos. Mallart faz uso, de um lado, de uma perspectiva relativista, não procurando em sua narrativa escolher a quem pertence a verdade do funcionamento das Fundações CASA e, de outro, enfatiza os processos pelos quais se constroem e se manejam nesses mundos as linhas de força e os jogos de poder em detrimento de focalizar seu olhar em regras e seus possíveis - ou não - descumprimentos. Assim, o pesquisador consegue traçar os universos que compõem e são produzidos a partir da Fundação CASA, enfatizando as redes mutáveis formadas entre adolescentes e seus familiares, agentes penitenciários, códigos formais e informais de conduta e organismos públicos e não governamentais.

O livro é dividido em quatro capítulos principais, além de uma seção para considerações finais. Cadeias dominadas traz ainda um prefácio escrito por Vera 
Sílvia Telles, presente na defesa de sua dissertação, e um posfácio de Rose Satiko Hikiji, sua orientadora ao longo do mestrado. Acima dessa divisão proposta pelo autor, enfatizo uma singularidade que atravessa sua obra: a construção dos termos da narrativa é baseada na trajetória de internos e ex-internos e é a partir dela que as instituições pelas quais passa o autor ganham carne, osso e sangue. Túlio, Pedro e Lucas, todos nomes fictícios, são as personagens reais dessa trama envolvente de Cadeias Dominadas.

Pouco a pouco no livro esta trama vai se revelando mais e mais complexa, imbricada com fatores, atores e situações em constante processo de transformação. Ressalto neste momento a posição ocupada por Fábio Mallart em sua inserção na Fundação CASA, antiga FEBEM (Fundação Estadual do Bem-Estar do Menor). $O$ autor descobriuse antropólogo ao longo de seu trabalho realizado junto a diversas unidades como agente cultural. Foi principalmente como professor de cursos de fotografia que teve entrada em campo; desse acesso, entretanto, o pesquisador construiu seu material narrativo, fotografando o cotidiano e escrevendo dia após dia seu caderno de campo. Descobriu seus problemas de pesquisa enquanto, por assim dizer, vivenciava-os na pele. Essa inserção de Mallart torna-se emblemática em um dos eventos etnográficos trazidos em Cadeias dominadas; evento que, analisado, torna possível traçar a riqueza desses mundos pesquisados pelo autor.

Em 2006, o antropólogo recebeu um pedido inusitado. Colocado pelos frente da cadeia, pelos piloto e pelos faxina em um quarto escuro e mal ventilado, recebe dos adolescentes um pedido: trazer para eles um pouco de maconha. O processo transcorreria normalmente, já que as coisas estavam todas acertadas lá fora, no mundão; o pesquisador apenas deveria se encarregar do transporte e estava recebendo tal incumbência somente por ser de confiança dos jovens dali. Sentindo-a em seu corpo (pelo suor, pela tremedeira, pelos pesadelos que passaram a atormentá-lo), não aceitou tal proposta, explicando os dilemas éticos ali envolvidos e as possíveis consequências que poderiam se desenrolar a partir de uma ação como essa. Preocupado com sua negativa, o autor questiona os adolescentes se o episódio abalaria suas relações. "[...] Trazendo ou não o que nóis pediu, a relação de respeito vai continuar sendo a mesma" (Mallart 2014: 33), é o que respondem. Ao se opor ao pedido feito, o autor mostrou, para aquele mundo e para os jovens internos, que suas palavras não faziam curva e que fechavam com o certo, pois não mudavam de uma hora para outra a depender das circunstâncias, permanecendo sempre fiéis aos seus objetivos.

Aqui, cabe nos perguntarmos: e, por que o título da obra? Por que Cadeias Dominadas quando estamos, na verdade, tratando de instituições responsáveis por menores, por "adolescentes em conflito com a lei"? Crianças e adolescentes que estão internados nas múltiplas Fundações CASA do Estado de São Paulo denominam seus espaços como cadeias. Os motivos são muitos: desde o tratamento conferidos por agentes penitenciários, passando pelas condições de enclausuramento (superlotação, torturas, grades, solitárias e péssimos cuidados quanto à alimentação e à higiene), até o mais simbólico deles. Não se trata somente de semelhanças estruturais entre presídios e fundações; notável aí é a forma com que os adolescentes executam suas ações, vinculando suas experiências em cárcere às de seus irmãos de PCC (Primeiro Comando da Capital), presentes em boa parte das penitenciárias do estado e em outras regiões do Brasil.

As cadeias dominadas são, no contexto das Fundações CASA, aquelas em que os adolescentes estão no comando, sendo responsáveis pela gestão cotidiana daquele universo, ditando regras de comportamento e de socialização, 
enfim, participando ativamente, na maioria das vezes a contragosto das lideranças burocráticas, na condução da cadeia. Nesses espaços, prevalece o que é certo e a disciplina, segundo dizem os interlocutores de Mallart, e não são tolerados espancamentos, torturas, estupros e, sobretudo, guerra entre irmãos, aliados que são contra o sistema opressor que é o penitenciário. Reina, ainda que por breves momentos, a paz entre ladróes, na qual o inimigo deve quase nunca ser um adolescente na mesma situação de "cumprimento de medida socioeducativa". É nessas cadeias dominadas em que situações como a vivenciada pelo antropólogo se tornam mais prováveis e em que é possível ver pelos corredores uma pirâmide hierárquica estabelecida entre os adolescentes: pilotos, faxina, setores e torres são os principais responsáveis por gerir o espaço da cadeia, por fazê-la funcionar e por fazer com que os adolescentes prevaleçam sobre os funça, os administradores da unidade da Fundação.

O livro é excepcionalmente rico neste ponto: se há lideranças, o autor vai atrás de como elas se constituem, o que as leva a assumir um posto de autoridade em meio a dezenas e centenas de jovens conhecidos como população, por não estarem nessas mesmas posições. Como, então, sobressaem uns em relação aos demais? A partir da narrativa de seus três principais interlocutores, o pesquisador mostra a relevância da caminhada, categoria que arriscaria dizer ser central tanto para o autor quanto para o universo dos adolescentes internos da Fundação CASA. Caminhadas são os processos, as histórias, as relações e as opiniões desses jovens em seus momentos de internação. A depender do que se passou nas cadeias, do tipo e da quantidade de crimes que se cometeu, a depender de as palavras fazerem curva ou não, certas pessoas podem assumir situações de comando. Não estamos no campo das horizontalidades plenas, mas das hierarquias fundadas em objetivos e propósitos comuns. As posições de comando, a bem da verdade, nunca pertencem a indivíduos determinados; são ora preenchidas por uns ou por outros, com o objetivo claro de fazer prevalecer o certo; o certo entre os que estão trancafiados, a justiça entre aqueles que ali sofrem os processos penosos da internação.

Fábio Mallart enriquece ainda sua etnografia ao mostrar que não existem somente as unidades dominadas, aquelas nas mãos dos adolescentes e crianças. Os jogos de força que se estabelecem entre os múltiplos agentes abarcados pelo rol institucional da Fundação CASA engendram outras possibilidades de configurações de poder. Assim como há unidades em que os adolescentes, na medida do possível, controlam seu próprio cotidiano, há aquelas em que as cadeias estão nas mãos dos funça. Aí, o predomínio das lideranças passa por um decréscimo de protagonismo e se tornam mais frequentes violações aos corpos, abusos de poder e interrupção de atividades educacionais. As linhas de força, pode-se dizer, pendem aqui mais para as mãos de funcionários e de burocratas. É o mundo do licença, senhor, licença, senhora, do disciplinamento estrito. Nesse processo permanente de conflitos entre agentes institucionais e os agentes internados, não há possíveis previsões acerca de como serão os próximos meses de uma cadeia. Ora os poderes estão aqui, ora acolá, e vez ou outra estão mesmo divididos, quando os adolescentes categorizam tal circunstância de unidade meio a meio, denominação mais que autoexplicativa.

Os jogos de poder e as linhas tensas de força que se firmam entre aqueles que vivem nas Fundações CASA são, sem nenhuma dúvida, o grande fio condutor da narrativa da obra e são, acima disso, uma escolha metodológica elogiável. Ao entrar a fundo nas trajetórias de internos e ex-internos, o pesquisador consegue captar e focalizar uma instituição (rodeada de muitas outras, como a Secretaria de Justiça e Defesa de Cidadania 
do Estado de São Paulo e as organizações não-governamentais voltadas ao tema dos direitos humanos) em seus processos de metamorfose. Com vocês, o próprio autor:

[...] Nota-se que o próprio universo institucional, ao mesmo tempo em que se move ininterruptamente na medida em que as relações travadas entre os distintos atores sociais que o constituem o deslocam, carrega consigo a permanência de determinados elementos que persistem ao longo do tempo. Em outras palavras, no que concerne à dinâmica institucional, continuidade e mudança coexistem. (Mallart 2014: 88)

As trajetórias narradas ao longo de Cadeias Dominadas permitem ao leitor ter noção clara desse processo que é único, porque integra um conjunto de dispositivos próprios desse universo institucional do encarceramento, embora também ambíguo, porque permeado por muitas nuances que só depoimentos e convivências etnográficas nos possibilitam ver em melhor perspectiva. Das FEBEMs às Fundações CASA muitas coisas mudaram e, em especial, o tratamento destinado aos adolescentes. Se antes, atendiam-se também, além de "jovens em conflito com a lei", aqueles que eram abandonados ou viviam em "situações de rua", posteriormente, o foco passa a ser unicamente sob possíveis autores de ato infracional. Transformam-se também as escalas arquitetônicas dos espaços prisionais: de grandes construções às pequenas e mais numerosas unidades. Intenção clara aqui: conter, disciplinar, isolar. A função "ressocializadora", no mais das vezes, passa longe de toda e qualquer ação rotineira empregada por aqueles na direção das unidades.

A palavra "ressocialização" é valiosa nesse momento. O trabalho de pesquisa é minucioso também aqui: afinal de contas, esses jovens não estão nem nunca estiveram fora da sociedade. Convivem com seus familiares em dias de visita, mas estendem seus relacionamentos para além desses momentos institucionalmente marcados. As quebradas, o mundão, isto é, tudo que não está intramuros, e as cadeias estão quase sempre em sintonia, operando em conjunto, funcionando dentro de uma rede de relacionamentos em constante transformação e sob permanente reinvenção. Não há cadeias que se encerram nas celas e nos muros eletrificados dos presídios, nem indivíduos que, por estarem trancafiados, estejam apartados da vida social. Estão, como é de se esperar, sempre nela, agenciando com o que e com quem puderem, nesses jogos de forças instáveis que subjazem às rotinas das Fundações CASA.

Cadeias dominadas se afasta, portanto, da solução fácil de ver as Fundações CASA como instituições totais, voltadas para o completo condicionamento de seus membros, em cujos corredores o menor deslize se configuraria como atentado à ordem. Fábio Mallart se mostra em sua obra como antropólogo das táticas, das estratégias e dos processos e, sobretudo, perspicaz ao não tomar o discurso oficial como dado e ser capturado por ele. Suas palavras, eu diria, não fazem curva do início ao fim da obra.

Recebido em: 28/04/2015

Aprovado em: 17/06/2015
Vinícius Prado Januzzi é Mestrando em Antropologia pela Universidade de Brasília (UnB). 